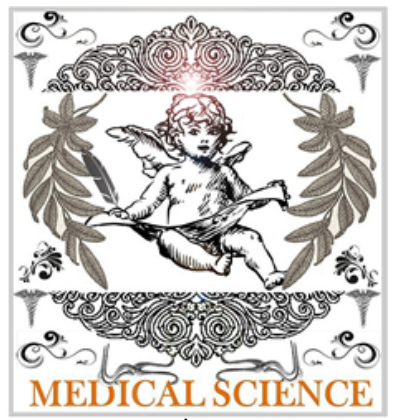

\title{
Medical Science: Towards Better Standard and Quality
}

\section{Banerjee I*}

\section{Corresponding Author:}

*Indrajit Banerjee MBBS, MD Pharmacology, Lecturer, MCOMS Email: indrajit18@gmail.com

Full list of author information is available at the end of the article

With great pleasure I am writing few words for the new Journal It gives me immense pleasure to write the editorial of the esteemed journal Medical Science. Medical Science is an official Journal of Confederation of Medical Research Associations (CMRA). It is a multidisciplinary journal which encompasses of Medical, Nursing, Dental and Allied health sciences [1]. It is a peer reviewed journal and a milestone in scientific field and research [2].

The first issue of the journal has been published in June 2013. All the papers of the first issue are having good quality and high standard. Articles were published from various topics namely Medical Education [3, 4] Pharmacology [5, 6] Statistics [6], and Psychiatry [6].

The editorial board members are highly qualified scientists from various fields and institutions. Dr. Pradhan who is at present the Chief Editor of Medical Science is a famous researcher and educator from India. Dr. Roy is a well known researcher who is at present the Associate Chief Editor of Medical Science is expertise in the Medical education, Physiology and Neuroscience. He has published abundant papers in his field. Some of his recent papers are published in reputed journals [710].

Dr. Sathian is a well-known scientist he has published lots of articles and books too. Among which the Relevance of Sample Size determination in medical research and reporting dichotomous data using logistic regression in medical research: the scenario in developing countries are highly cited articles from Nepal [11,12].

The article by Dr. Sathian published in Journal of Clinical and diagnostic Research is among the most popular articles of the journal. It has is having 22506 views till 28th August 2013[13]. I am also there in the editorial team at present I am the section editor of Medical Science. I am the first MD Pharmacology of Kathmandu University from Nepal. Some of my recent papers are published in reputed journals of Nepal and abroad [14-20]. Among the articles two are the highest viewed articles in the journals like Asian Journal of Medical Sciences and Nepal journal of Epidemiology. Medications for Anxiety: A Drug utilization study in Psychiatry Inpatients from a Tertiary Care Centre of Western Nepal and Student's Accreditation of integrated Medical Education in Nepal are the mostly viewed article. $[16,19]$.

Journal policies of Medical Science are also transparent. The CV of most of the editorial board members along with their contact details is available in the journal website. Medical Science has got a very convenient submission process. Article can be submitted by two processes namely online submission and via email submission. Authors can directly contact the editors by sending mails at medicalscience.pubmedhouse.com or medical.science.pubmed@gmail.com. Medical Science is a quarterly published journal. Within a very short period of time the journal is indexed in Ulrichsweb, Directory of Open Access Journals (DOAJ), Socolar, Journal index, Index scholar, International Society of Universal Research in Sciences, Jourinfo, Jadounscience, Newjournal, Research Bible, and it is planned for EMBASE, PubMed and PubMed Central in future.

At last I would like to congratulate the Chief Editor and the whole editorial team of Medical Science for taking this initiative to start and publishing the first issue of the esteemed journal. I wish all the best for the upcoming issue. 


\section{Authors' information}

*Dr. Indrajit Banerjee MBBS, MD Pharmacology. Currently working as a Lecturer in the Department of Pharmacology, Manipal College of Medical Sciences, Pokhara, Nepal.

\section{References}

1. Roy B. Preface To First Edition. Medical Science 2013;1(1): 19-23.

2. Banerjee I. Medical Science: A milestone in scientific field and research. Medical Science;1(2):26-27.

3. Roy B, Banerjee I, Banerjee I, Sathian B, Baboo NS. Impact of Gender, Nationality and Drawbacks in Medical Profession as a Predictor of Future Career Specialization among Medical Students. Medical Science 2013;1(1): 3-11.

4. Kumar S. Use of computer among medical students: A cross sectional study. Medical Science 2013;1(1): 15-18.

5. Banerjee I. Teaching Communication Skills: A five year experience from a private medical school of Nepal. Medical Science 2013;1(1): 12-14.

6. Banerjee I, Banerjee I, Roy B, Sathian B. Application of Binary Regression Analysis in the Prescription Pattern of Antidepressants. Medical Science 2013;1(1): 19-23.

7. Roy B, Banerjee I, Sathian B. Importance of logistic regression to obtain willingness for future specialization in medicine and surgery among undergraduate students. National Conference on Medical Statistics. ISMSCON 2012.30TH Annual National Conference of Indian Society for Medical Statistics.

8. Roy B, Banerjee I, Sathian B, Mondal M, Kumar SS, Saha CG. Attitude of Basic Science Medical Students towards Medicine and Surgery Post Graduation: A Questionnaire based Cross-sectional Study from Western Region of Nepal. Nepal Journal of Epidemiology 2012; 1(4):126-134.

9. Roy B, Banerjee I, Sathian B, Mondal M, Saha CG. Blood Group Distribution and Its Relationship with Bleeding Time and Clotting Time: A Medical School Based Observational Study among Nepali, Indian and Sri Lankan Students. Nepal Journal of Epidemiology 2012; 1(4):135-140.

10. Banerjee I, Jauhari A C, Bista D, Johorey A C, Roy B, Sathian B. Medical Students View about the Integrated MBBS Course: A Questionnaire Based Cross-sectional Survey from a Medical College of Kathmandu Valley. Nepal Journal of Epidemiology 2011;1(3): 95-100.
11. Sathian B, Sreedharan J, Baboo NS, Sharan K, Abhilash ES, Rajesh E. Relevance of Sample Size Determination in Medical Research. Nepal Journal of Epidemiology 2010, 1(1):4-10.

12. Sathian B. Reporting dichotomous data using Logistic Regression in Medical Research: The scenario in developing countries. Nepal Journal of Epidemiology 2011, 1(4):111-113.

13. Sathian B, Sreedharan J , Sharan K, Suresh B N , Ninan J , Joy T, Et Al. Forecasting Breast Cancer Cases requiring Radiotherapy at a Teaching Hospital in Nepal. 2010;4(3): 2378-2383.

14. Banerjee I. Teaching Communication Skills: A five year experience from a private medical school of Nepal. Medical Science 2013;1(1): 12-14.

15. Banerjee I, Roy B , Sathian B , Banerjee I, Chakraborty PK. Application of Regression analysis in the utilization of Antipsychotic drugs: A hospital based study from Western Nepal. National Conference on Medical Statistics. ISMSCON 2012.30TH Annual National Conference of Indian Society for Medical Statistics

16. Banerjee I, Roy B, Sathian B, Banerjee I, Kumar SS, Saha A: Medications for Anxiety: A Drug utilization study in Psychiatry Inpatients from a Tertiary Care Centre of Western Nepal. Nepal Journal of Epidemiology 2010, 1(4):119-25.

17. Banerjee I, Roy B, Banerjee I, Sathian B, Mondol M, Saha A: Depression and its Cure: A Drug Utilization Study from a Tertiary Care Centre of Western Nepal. Nepal Journal of Epidemiology 2011, 1(5):144-52.

18. Banerjee I, Roy B, Sathian B, Banerjee I, Chakraborty PK, Saha A. Socio demographic profile and utilization pattern of antipsychotic drugs among schizophrenic inpatients: a cross sectional study from western region of Nepal. BMC Psychiatry. 2013 Mar 22;13:96.

19. Banerjee I, Jauhari CA, Johorey CA, Gyawali S, SahaA. Student's Accreditation of integrated Medical Education in Nepal. Asian Journal of Medical Sciences .2011;2 (1): 49-52.

20. Banerjee I. Concepts of P-drug selection. Nepal Journal of Epidemiology 2013;3(1):226-229. 